\title{
A Vortex-Assisted Deep Eutectic Solvent-Based Liquid-Liquid Microextraction for the Analysis of Alkyl Gallates in Vegetable Oils
}

\author{
Hasan Çabuk, ${ }^{*}$ Yasemin Yılmaz and Elif Yıldız \\ Zonguldak Bülent Ecevit University, Faculty of Arts and Sciences, Department of Chemistry, 67100, Zonguldak, Turkey \\ * Corresponding author: E-mail: cabukhasan@hotmail.com \\ Tel.: 0090372291 1920; Fax: 00903722574181
}

Received: 11-27-2018

\begin{abstract}
This study investigates the feasibility of using hydrophilic deep eutectic solvent (DES) as green and effective extractant for the extraction and preconcentration of alkyl gallates from vegetable oils. In a typical experiment, $120 \mu \mathrm{L}$ of choline chloride:ethylene glycol DES was added to $1.0 \mathrm{~g}$ of oil sample which was previously diluted with $1 \mathrm{~mL}$ of $n$-hexane. The extraction was accelerated by vortex stirring of the two phases. At this stage, hydrogen bonding interactions between the phenyl hydroxyls of alkyl gallates and chloride anion of choline salt were likely the main forces driving the extraction. After extraction, the analytes in the DES phase were separated and determined by high-performance liquid chromatography with ultraviolet detection. The method detection limits for propyl gallate and octyl gallate were 2.1 and $4.6 \mu \mathrm{g} \mathrm{kg}^{-1}$, respectively. The precision of the method varied between $4.6-6.4 \%$ (intra-day) and 5.4-7.5\% (inter-day). The recoveries (accuracies) obtained from spiked vegetable oil samples were in the range of $78-106 \%$.
\end{abstract}

Keywords: Deep eutectic solvent, alkyl gallates, vegetable oils, high-performance liquid chromatography

\section{Introduction}

Synthetic antioxidants (SAs) are a class of compounds which are capable of preventing or slowing down the oxidation reactions of substrates in food, pharmaceuticals, and other consumer products. ${ }^{1}$ Common SAs used as food additives in many countries include butylated hydroxyanisole, butylated hydroxytoluene, tert-butylhydroquinone, propyl gallate, octyl gallate and dodecyl gallate, due to their chemical stabilities, low costs and availabilities. ${ }^{2}$ Among SAs, alkyl gallates have been widely used as food additives to slow down or prevent lipid oxidation in lipid-rich food. ${ }^{3}$ Contrary to their versatile and beneficial properties, the addition of excess gallates to food might cause different degrees of adverse and toxic effects on human health. They can induce DNA damage and mutagenicity, and their antioxidant potential can turn pro-oxidant under certain conditions. ${ }^{2,4}$ Therefore, the use of gallates as well as other SAs is strictly controlled in many countries worldwide. Generally, the allowed amounts of SAs in food range from 100 to $200 \mathrm{mg}$ $\mathrm{kg}^{-1}$ in European Union, either singly or in combination. ${ }^{5}$

The determination of alkyl gallates in foodstuffs has been accomplished using specific electrochemical sen- sors $^{6-8}$ and different separation techniques such as high-performance liquid chromatography (HPLC), ${ }^{5,9-12}$ micellar electrokinetic capillary chromatography ${ }^{13,14}$ and capillary electrophoresis. ${ }^{15,16}$ Electrochemical methods may offer relatively low operational costs and faster analysis. However, in the case of multiple analytes they require chemometric interpretation of the overlapping electrochemical signals for the estimation of individual analyte concentrations. ${ }^{17}$ Among the separation techniques, HPLC with ultraviolet (UV) detection has become the most widely used technique for the determination of alkyl gallates following the extraction by liquid-liquid extraction (LLE) of the sample. Acetonitrile, previously saturated with $n$-hexane, is the most preferred solvent for extracting alkyl gallates from oil samples. ${ }^{9,12}$ To a lesser extent, methods based on the direct injection of a diluted oil sample into the HPLC system have also been used. ${ }^{18,19}$ However, a pretreatment step for sample enrichment and cleanup is always desirable prior to any chromatographic analysis due to the complexity of the sample matrix. Recently, some novel microextraction procedures, such as cloud-point extraction $(\mathrm{CPE})^{10}$ and dispersive liquid-liquid microextraction (DLLME) $)^{5,20}$ have also been devel- 
oped to detect alkyl gallates in oil samples as greener alternatives to classical LLE. In the last few years, the majority of the innovative studies on microextraction procedures are concerned with replacing toxic organic solvents with environmentally friendly ones, including supramolecular solvents, ionic liquids and deep eutectic solvents (DESs).

DESs are regarded as new generation green solvents because of their attractive properties such as easy synthesis, low cost, low volatility, high biodegradability, and feasibility of structural design. ${ }^{21} \mathrm{~A}$ DES is typically prepared by mixing an appropriate amount of a hydrogen bond acceptor (HBA) and a hydrogen bond donor (HBD). The resulting mixture has a lower melting point than that of each individual component, which makes it liquid at room temperature. The formation of hydrogen bonding between the DES components is responsible for the decrease in the melting point. ${ }^{22}$ The most common DESs are based on choline chloride $(\mathrm{ChCl})$ paired with various $\mathrm{HBDs}$, the most popular ones being urea, ethylene glycol, and glycerol, but other alcohols, amino acids, carboxylic acids, and sugars have also been used. ${ }^{23}$ Due to their unique physicochemical characteristics, DESs have the potential to replace conventional organic solvents in separation and extraction processes. However, due to the hydrogen bonding ability of DESs, they are generally hydrophilic which restricts their application as extraction solvents in aqueous samples. ${ }^{24}$ Therefore, the major applications have focused on the extraction of naturally occurring compounds from organic liquid samples (mainly vegetable oils) and solids (plants and foods). Phenolic compounds, ${ }^{25,26}$ flavonoids ${ }^{27,28}$ and terpenoids ${ }^{29}$ are the most commonly determined bioactive compounds, with extraction procedures based on the use of hydrophilic DESs. Very recently, hydrophobic DESs combining quaternary ammonium salts, thymol or menthol with alkyl carboxylic acids have also been prepared and used for the extraction of pesticides, ${ }^{30}$ polycyclic aromatic hydrocarbons ${ }^{31}$ and benzophenonetype UV filters ${ }^{32}$ from water samples. DESs possess tunable solvent properties that make them highly efficient in extracting compounds from different chemical classes. With respect to SAs, tert-butylhydroquinone is the only analyte that has been determined in vegetable oils with the extraction procedures based on the use of $\mathrm{ChCl}$ :ascorbic acid, ${ }^{33} \mathrm{ChCl}$ :sesamol ${ }^{34}$ and $\mathrm{ChCl}$ :ethylene glycol ${ }^{35}$ compositions. However, as far as we know, there is no DES-based extraction method reported in the literature for alkyl gallates. Therefore, the aim of this study was to investigate the feasibility of using a hydrophilic ChCl-based DES as an extraction solvent for the extraction and preconcentration of alkyl gallates including propyl gallate and octyl gallate (see their structures and some relevant data in Table 1) from vegetable oils. The dispersion of DES phase into the vegetable oil was achieved using vortex stirring, and then the resulting methodology was termed vortex-assisted DES-based liquid-liquid microextraction (VA-DESLLME). Following the microextraction process, alkyl gallates in DES phase were separated and determined by HPLC-UV.

\section{Experimental}

\section{1. Reagents and Samples}

All of the reagents used in the experiments were of analytical grade $(\geq 98 \%)$. Ethylene glycol, glycerol, urea, choline chloride $(\mathrm{ChCl})$, propyl gallate, octyl gallate and acetonitrile (ACN) were obtained from Sigma-Aldrich (Steinheim, Germany). Triflouroacetic acid (TFA) and $n$-hexane were purchased from Merck (Darmstadt, Germany). Isopropyl alcohol was provided from Kimetsan (Ankara, Turkey). Water was used after purification with a Milli-Q system (Millipore, Bedford, MA, USA).

Stock standard solutions were prepared in acetonitrile at a concentration of $100 \mu \mathrm{g} \mathrm{mL} \mathrm{m}^{-1}$ and stored at $4{ }^{\circ} \mathrm{C}$ for one month. The working solutions at different concentrations were freshly prepared in isopropyl alcohol and used for the spiking of the oil samples. Spiked samples were mixed well for the complete dissolution of the antiox-

Table 1. Chemical structure and properties of the selected alkyl gallates.

Analyte Structure

Çabuk et al.: A Vortex-Assisted Deep Eutectic Solvent-Based ... 
idants in the oil matrix before being extracted. The vegetable oil samples including sunflower oil, corn oil and hazelnut oil were collected from local supermarkets in Zonguldak, Turkey. The collected oil samples were packed in screw-cap glass tubes and stored at room temperature until analyzed.

\section{2. Instrumentation and Chromatographic Conditions}

The HPLC system (Thermo Finnigan, San Jose, USA) consisted of a P1000 pump, a AS3000 automatic injector system, and a UV1000 UV detector. The system was controlled by a Spectra System Controller SN 4000 and a software package ChromQuest 4.0. A Phenomenex $\mathrm{C}_{12}$ Max-RP column $(250 \times 4.6 \mathrm{~mm}$ i.d., $4.0 \mu \mathrm{m})$ was used for separations. The mobile phase consisted of $\mathrm{ACN}$ and water with $0.1 \%$ TFA. The optimized elution program was set at $1.0 \mathrm{~mL} \mathrm{~min}{ }^{-1}$, starting with $40 \%$ acetonitrile and then a linear gradient elution from 40 to $90 \%$ acetonitrile at 20 min. Next, 10 min was necessary for returning to the initial conditions. Before another injection, the system was permitted to stabilize for 5 min under the initial conditions. The UV monitoring wavelength for quantification was set to $280 \mathrm{~nm}$. The injection volume was $20 \mu \mathrm{L}$. A Perkin Elmer Frontier Fourier transform infrared (FT-IR) spectrometer with a diamond attenuated total reflectance (ATR) attachment was used to determine the functional groups of DESs. A magnetic stirrer (RSM-01H, Phoenix, Garbsen, Germany), a vortex mixer (SA8, BioCote, UK), a centrifuge (NF 200, Nuve, Ankara, Turkey) were used in the sample preparation step. A Kern ABJ 220-4 M model analytical balance (Kern \& Sohn, Germany) was used for weighing the samples and standard materials.

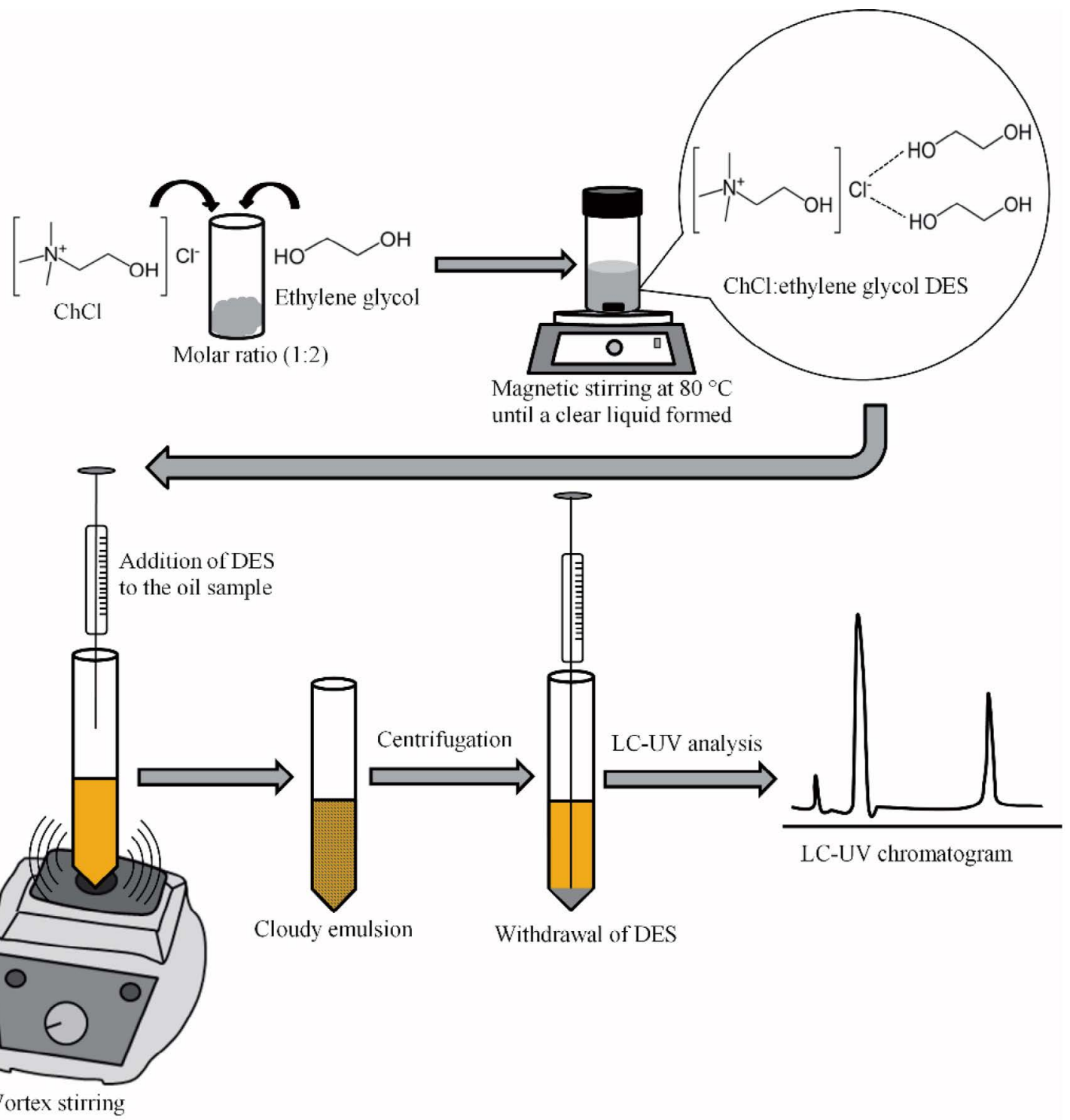

Figure 1. Schematic diagram of the preparation of ChCl:ethylene glycol DES and VA-DES- LLME method. 


\section{3. Preparation of DESs}

DESs were prepared by mixing $\mathrm{ChCl}$ with $\mathrm{HBD}$ (ethylene glycol, glycerol, or urea) at a constant molar ratio of 1:2 in screw-capped bottles. The mixture was stirred at a temperature of $80^{\circ} \mathrm{C}$ until a clear liquid was formed. Figure 1 shows, as an example, the schematic of the preparation of ChCl:ethylene glycol DES. All DESs were used in the experiments without any further purification.

\section{4. VA-DES-LLME Procedure}

Figure 1 shows the schematic of the VA-DES-LLME procedure. Oil sample $(1.0 \mathrm{~g})$ was accurately weighed into a $12 \mathrm{~mL}$ glass test tube with conical bottom and diluted with $1.0 \mathrm{~mL}$ of $n$-hexane, to which $120 \mu \mathrm{L}$ of DES as extracting solvent was added. Afterwards, the mixture was vortex-stirred at $2500 \mathrm{rpm}$ for $5 \mathrm{~min}$ and then centrifuged at $4000 \mathrm{rpm}$ for $5 \mathrm{~min}$. Finally, the DES extract was collected with a microsyringe and transferred to a glass vial for the HPLC-UV analysis.

\section{Results and Discussion}

Optimization of VA-DES-LLME was carried out using $1.0 \mathrm{~g}$ of sunflower oil sample, spiked with propyl gallate and octyl gallate at a concentration of $1.25 \mu \mathrm{g} \mathrm{g}^{-1} \mathrm{each}$. The type of DES, volume of diluent solvent, volume of DES and vortex stirring time were the variables investigated. The optimal conditions were selected based on the extraction recoveries (ERs) of the alkyl gallates. The ER was calculated based on the ratio of the amount of the analyte determined in the collected DES phase to the initial amount of analyte added in the sample. All the experiments were carried out in triplicate.

\section{1. Effect of the Types of DESs}

The composition of DESs determines their physicochemical properties such as density, viscosity, and surface tension and consequently influences extraction efficiency of the target analytes. With the aim to select the most suitable DES for extraction of alkyl gallates from vegetable oils, three different $\mathrm{ChCl}$-based DES, which contained ethylene glycol, glycerol, and urea as the HBDs at a constant molar ratio of 1:2 were tested. In all cases, aliquots of $1.0 \mathrm{~g}$ of sunflower oil sample were extracted with $100 \mu \mathrm{L}$ of DES under vortex stirring for $5 \mathrm{~min}$. When ChCl:urea DES was used, it was not effectively dispersed into the oil sample with vortex stirring. In addition, it could not be withdrawn into the micro-injector prior to chromatographic analysis. On the contrary, these difficulties were not observed when ethylene glycol and glycerol-based DESs were tested. The results observed here could be attributed to the difference in their viscosities and other physical properties. The ChCl:urea DES has much higher viscosity $(750 \mathrm{cP})$ than those of the ChCl:ethylene glycol DES ( $37 \mathrm{cP}$ ) and ChCl:glycerol DES $(259 \mathrm{cP})$ at $25^{\circ} \mathrm{C}^{38}$ Most DESs have higher viscosities $(>100 \mathrm{cP})$ than other molecular solvents due to the presence of extensive hydrogen-bonding interactions between the components, which slows down the mass transfer of the analytes to the extraction media. ${ }^{23}$ Addition of water, in general, reduces the viscosity of these solvents, and therefore allows better mass transfer rates. However, at the same time the presence of water may reduce the extraction yields due to the weakening of the hydrogen bond interactions between the solvent and the target compounds. ${ }^{39}$ Due to the opposite effects of water on the extraction efficiency, it was not investigated in the present experiment. As shown in Figure 2, the extraction efficiencies of ethylene glycol and glycerol-based DESs were close to each other, meaning that each of DESs could be used as a solvent for the extraction of alkyl gallates. However, Ch$\mathrm{Cl}$ ethylene glycol DES provided some advantages in the solvent transfer and injection stages due to its lower viscosity; thus, it was selected as extraction solvent in the subsequent experiments.

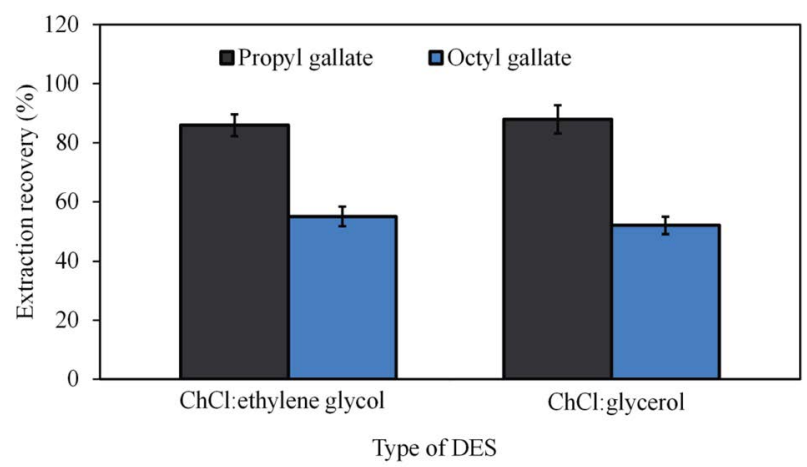

Figure 2. Effect of the type of DES. DES volume, $100 \mu \mathrm{L}$; vortex time, $5 \mathrm{~min}$.

\section{2. Characterization of $\mathrm{ChCl}$ :ethylene Glycol DES}

The formation of hydrogen bonding between the chloride anion of $\mathrm{ChCl}$ and ethylene glycol is the main force for the formation of DES. As shown in Figure 3, FT-IR spectra of $\mathrm{ChCl}$, ethylene glycol, and $\mathrm{ChCl}$ :ethylene glycol DES were investigated. According to the FT-IR spectra, the broad band at $3294 \mathrm{~cm}^{-1}$ related to the stretching vibration of the $\mathrm{O}-\mathrm{H}$ group in ethylene glycol shifted to $3303 \mathrm{~cm}^{-1}$ in ChCl:ethylene glycol DES. This shift towards higher wavenumber with the incorporation of $\mathrm{ChCl}$ and ethylene glycol was due to the decrease in the extent of intermolecular hydrogen bonding between ethylene glycol molecules. ${ }^{40}$ The spectrum of DES was dominated by ethylene glycol, however, an additional characteristic band at $953 \mathrm{~cm}^{-1}$ originating from $\mathrm{ChCl}$ was observed. This new band was attributed to the $\mathrm{C}-\mathrm{N}^{+}$stretching. In addition, DES presented vibrational bands at $2938 \mathrm{~cm}^{-1}$ and 2875 


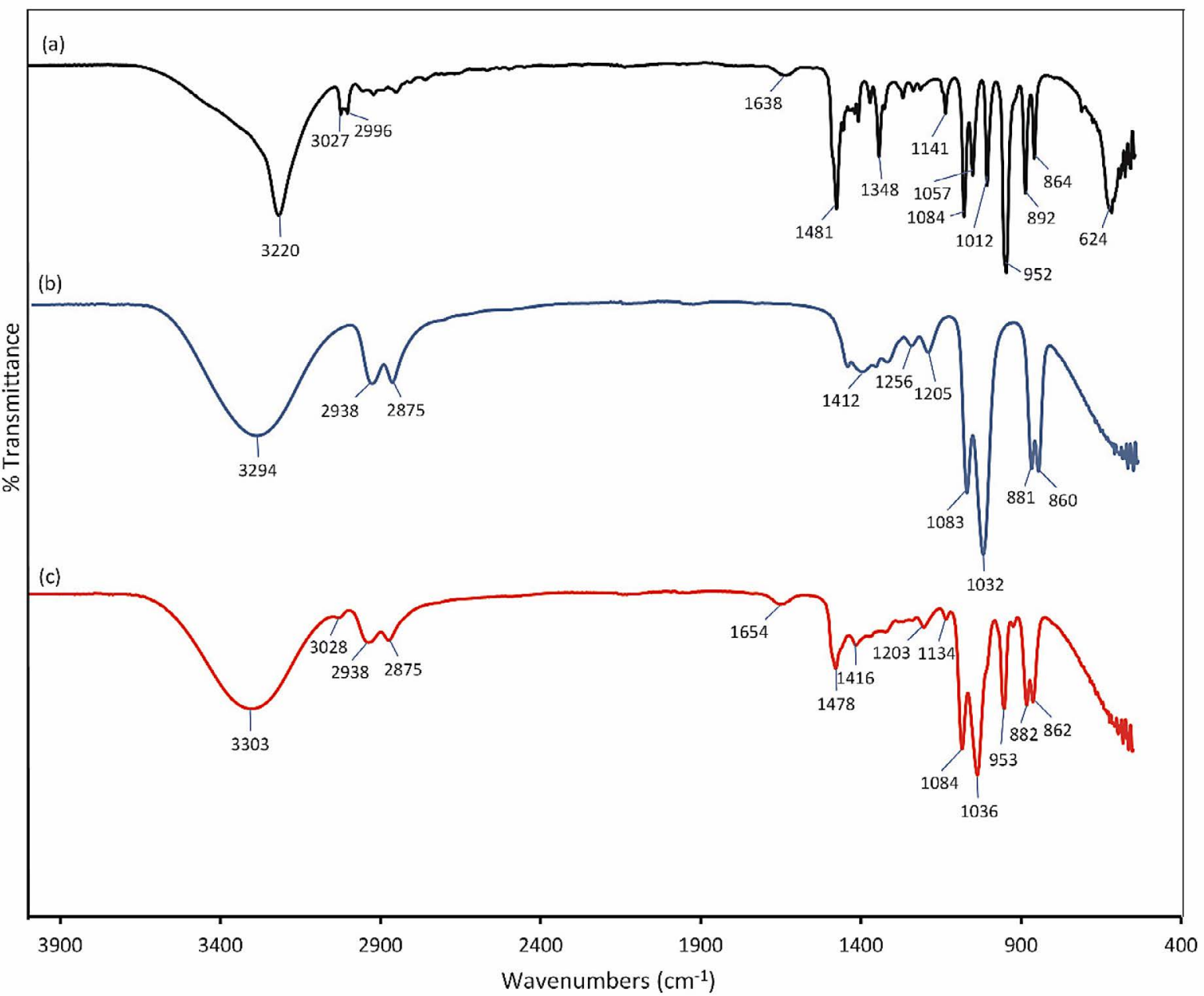

Figure 3. FT-IR spectra of (a) ChCl, (b) ethylene glycol, (c) ChCl:ethylene glycol DES.

$\mathrm{cm}^{-1}$ referring to $\mathrm{C}-\mathrm{H}$ stretching, $1478 \mathrm{~cm}^{-1}$ to the $\mathrm{CH}_{2}$ bending of an alkyl group, and $1084 \mathrm{~cm}^{-1}, 1036 \mathrm{~cm}^{-1}$, and $882 \mathrm{~cm}^{-1}$ to functional groups, namely $\mathrm{C}-\mathrm{O}$ stretching, $\mathrm{C}-\mathrm{C}-\mathrm{O}$ asymmetric stretching, and $\mathrm{C}-\mathrm{C}-\mathrm{O}$ symmetric stretching. ${ }^{41}$ These results indicated the successful synthesis of ChCl:ethylene glycol DES.

\section{3. Effect of the Volume of Diluent Solvent}

The dilution of oil sample with an appropriate solvent has a significant effect on the extraction efficiency since it reduces the viscosity of oil and facilitates the formation of the cloudy emulsion. In addition, the fat and other impurities are easily dissolved in the diluent solvent which may be beneficial for the removal of impurities. ${ }^{42}$ Hexane is the most preferred solvent owing to its low toxicity, low cost and high miscibility with the oil. ${ }^{43}$ In this work, $n$-hexane was selected as diluent solvent and the effect of its volume was studied in the range of $0-2 \mathrm{~mL}$. Aliquots of $1.0 \mathrm{~g}$ of sunflower oil sample were diluted with hexane and subjected to vortex stirring for 5 min with 100 $\mu \mathrm{L}$ of ChCl:ethylene glycol DES as extraction solvent. As shown in Figure 4, the extraction efficiency of alkyl gallates increased slightly as the hexane volume was increased from 0 to $1 \mathrm{~mL}$ and remained nearly constant over this volume. The reason could be that the viscosity of oil sample reduced with the increase of the volume of hexane, which facilitated the mass transfer of the analytes from oil

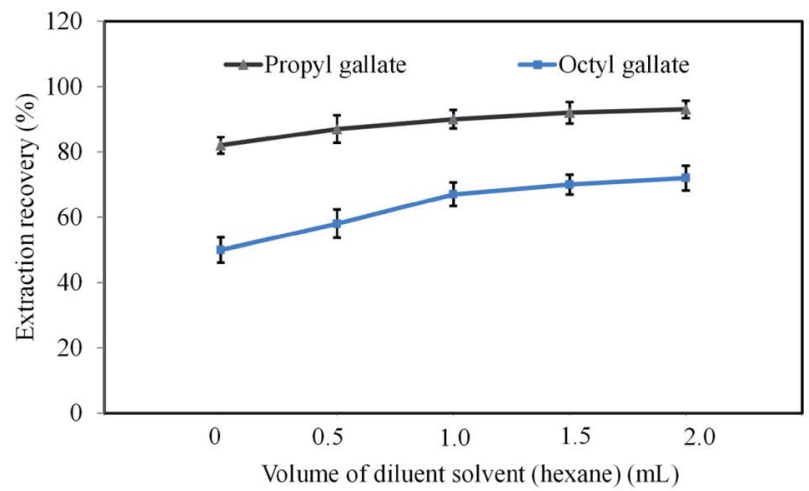

Figure 4. Effect of the volume of diluent solvent. DES, ChCl:ethylene glycol; diluent solvent, $n$-hexane; DES volume, $100 \mu \mathrm{L}$; vortex time, 5 min. 
to the DES phase. Therefore, the diluent solvent ( $n$-hexane) volume was selected as $1 \mathrm{~mL}$ for all further experiments.

\section{4. Effect of the Volume of DES}

Selection of the optimum volume for the extraction solvent is another important step in the majority of microextraction methods. By the increase of extraction solvent volume, the final solvent volume collected after centrifugation is increased, resulting in a decrease in sensitivity towards the analytes. In order to increase the sensitivity, it is essential to keep the volume of extraction solvent as low as possible. However, it is not always possible to reduce the solvent volume as desired, because a sufficient volume of solvent needs to be collected after centrifugation for the analysis. To examine the effect of the extraction solvent volume on the extraction efficiency, different volumes of ChCl:ethylene glycol DES from 60 to $140 \mu \mathrm{L}$ were investigated while the other experimental parameters, diluent solvent volume of $1 \mathrm{~mL}$ and vortex time of $5 \mathrm{~min}$, were kept constant. The volumes less than $60 \mu \mathrm{L}$ were not examined because of the difficulty in getting a separated DES phase. The obtained results (Figure 5) showed that the extraction efficiency increased with the increase of DES volume up to $120 \mu \mathrm{L}$ and remained unchanged after that. Typically, a higher volume of solvent requires a longer mixing time to be broken up into fine droplets; here above $120 \mu \mathrm{L}$, the extraction recovery did not further increase maybe due to the incomplete formation of fine droplets within a fixed vortex time. Therefore, $120 \mu \mathrm{L}$ was selected as the most suitable DES volume for subsequent experiments.

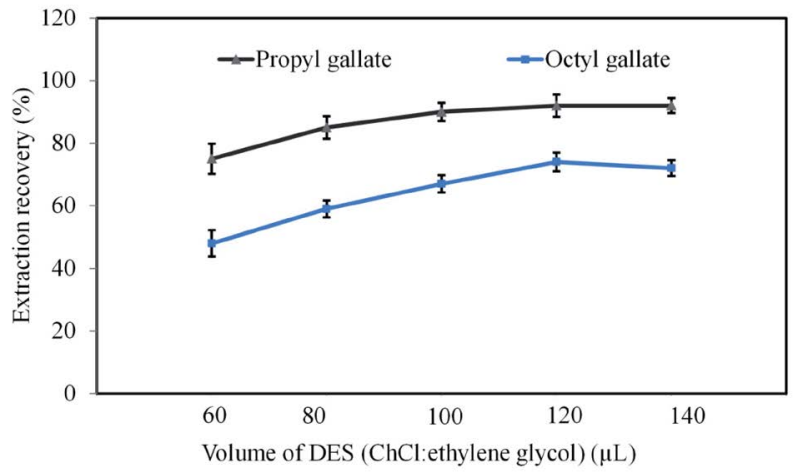

Figure 5. Effect of the volume of DES. DES, ChCl:ethylene glycol; diluent solvent, $n$-hexane; diluent solvent volume, $1 \mathrm{~mL}$; vortex time, $5 \mathrm{~min}$.

\section{5. Effect of Vortex Stirring Time}

The vortex stirring process facilitates the dispersion of the extraction solvent into the sample solution resulting in enhancement of extraction efficiency. The time required to reach extraction equilibrium under vortex stirring is an important parameter to be optimized. In this work, the vortex rotational speed was kept at maximum $(2500 \mathrm{rpm})$ and different vortex times were investigated, from 1 to $15 \mathrm{~min}$. The experimental conditions were fixed and included the use of $1 \mathrm{~mL}$ of diluent solvent ( $n$-hexane) and $120 \mu \mathrm{L}$ of ChCl:ethylene glycol DES. The results (Figure 6) showed that the extraction efficiency increased with the increasing vortex time from 1 to $3 \mathrm{~min}$, and then from 3 to $5 \mathrm{~min}$, there was either a slight increase or no change, depending on the analyte. No significant change was observed at vortex times longer than $5 \mathrm{~min}$. Therefore, $5 \mathrm{~min}$ was chosen as the optimum vortex time.

According to these results, the optimal conditions of this method for the determination of alkyl gallates were as follows: the type of DES was ChCl:ethylene glycol with a molar ratio of 1:2; the volume of diluent solvent (hexane) was $1 \mathrm{~mL}$; the volume of ChCl:ethylene glycol DES was $120 \mu \mathrm{L}$; and the vortex stirring time was $5 \mathrm{~min}$. Because the DES was not soluble in oil matrix, it could be collected after extraction without a significant loss in its volume.

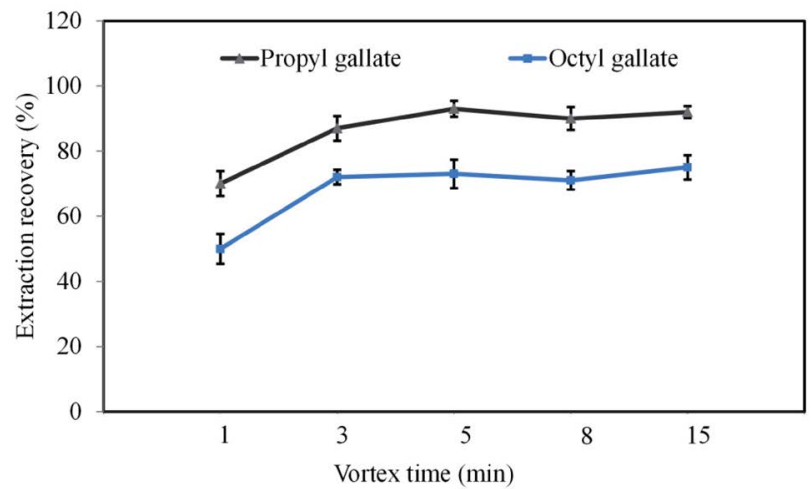

Figure 6. Effect of the vortex time. DES, ChCl:ethylene glycol; diluent solvent, $n$-hexane; diluent solvent volume, $1 \mathrm{~mL}$; DES volume, $120 \mu \mathrm{L}$.

Under the optimized conditions, the mean extraction recoveries for propyl gallate and octyl gallate were 93 and $73 \%$, respectively. The enrichment factors were also calculated based on the ratio of the analyte concentration in the DES phase to the initial analyte concentration in the oil phase. Under the optimized conditions, the mean enrichment factors for propyl gallate and octyl gallate were 8.5 and 6.7, respectively. Both propyl gallate and octyl gallate have the same $\mathrm{p} K_{\mathrm{a}}$ value of about $7.9,{ }^{36}$ meaning that their hydrogen bonding potentials are similar. The difference in the extraction efficiencies of alkyl gallates was then likely the result of their different hydrophobic characteristics. The octanol-water partition coefficients $\left(\log \mathrm{K}_{\mathrm{ow}}\right)$ for propyl gallate and octyl gallate are 2.6 and 5.2, respectively. ${ }^{37}$ The hydrophobicity of alkyl gallates increases with the increasing alkyl chain length (see the structures in Table 1), making the hydrophobic interaction between octyl gallate and oil stronger, and thus decreasing the hydrogen bonding strength between the phenyl hydroxyls of octyl gallate and chloride anion of choline salt. 


\section{6. Analytical Performance}

Linearity, limit of detection (LOD), limit of quantification (LOQ), and precision were investigated to verify the reliability of the method used in this study. The results are summarized in Table 2. Linearity was observed in the range of $0.01-5 \mu \mathrm{g} \mathrm{g}^{-1}$, with the square of correlation coefficients $\left(\mathrm{R}^{2}\right)$ higher than 0.9995 . LODs, based on a signalto-noise ratio $(\mathrm{S} / \mathrm{N})$ of 3 , ranged from 2.1 to $4.6 \mu \mathrm{g} \mathrm{kg}^{-1}$. The precision of the method was determined by analyzing the spiked samples at concentration level of $0.5 \mu \mathrm{g} \mathrm{g}^{-1}$ on the same day and on three different days. The relative standard deviations (RSDs) were in the ranges of $4.6-6.4 \%$ and $5.4-7.5 \%$ for intra-day $(n=5)$ and inter-day $(n=3)$ precision, respectively, which indicates that the method is repeatable.

\section{7. Real Samples Analysis}

The applicability of the proposed method was evaluated with three kinds of vegetable oil samples including sunflower oil, corn oil and hazelnut oil. The results indicated that the samples were free of alkyl gallates. To examine the applicability and accuracy of the method, all the samples were spiked at two concentration levels of 0.25 and 2.5 $\mu \mathrm{g} \mathrm{g}^{-1}$, and analyzed. The results are given in Table 3 . The recoveries of alkyl gallates from oil samples spiked at low and high concentration levels were $78-93 \%$ and $87-106 \%$, respectively. RSDs for these two levels were in the ranges $3.2-5.7 \%$ and $2.0-5.2 \%$. These results demonstrated that the matrix had a negligible effect on the extraction. Figure 7 shows, as an example, the HPLC-UV chromatograms of the alkyl gallates extracted from a sunflower oil sample be-

Table 2. Quantitative features of VA-DES-LLME method combined with LC-UV.

\begin{tabular}{|c|c|c|c|c|c|c|}
\hline Analyte & $\begin{array}{l}\text { Linear range } \\
\quad\left(\mu \mathrm{g} \mathrm{g}^{-1}\right)\end{array}$ & $\mathbf{R}^{2}$ & $\begin{array}{c}\text { LOD } \\
\left(\mu \mathrm{g} \mathrm{kg}{ }^{-1}\right)\end{array}$ & $\begin{array}{c}\text { LOQ } \\
\left(\mu \mathrm{g} \mathrm{kg}^{-1}\right)\end{array}$ & $\begin{array}{c}\text { Intra-day RSD } \\
\quad(\%, n=5)\end{array}$ & $\begin{array}{c}\text { Inter-day RSD } \\
\quad(\%, n=3)\end{array}$ \\
\hline Propyl gallate & $0.01-5$ & 0.9995 & 2.1 & 7.0 & 4.6 & 5.4 \\
\hline Octyl gallate & $0.01-5$ & 0.9996 & 4.6 & 15.3 & 6.4 & 7.5 \\
\hline
\end{tabular}

Table 3. Spiked recoveries (accuracies of determination) of alkyl gallates in vegetable oil samples.

\begin{tabular}{|c|c|c|c|c|c|}
\hline \multirow[t]{2}{*}{ Oil sample } & \multirow{2}{*}{$\begin{array}{c}\text { Added } \\
\left(\mu g^{-1}\right)\end{array}$} & \multicolumn{2}{|c|}{ Propyl gallate } & \multicolumn{2}{|c|}{ Octyl gallate } \\
\hline & & RR (\%) & $\operatorname{RSD}(\%, n=3)$ & RR (\%) & $\operatorname{RSD}(\%, n=3)$ \\
\hline \multirow{2}{*}{ Sunflower-1 } & 0.25 & 83 & 4.8 & 84 & 5.7 \\
\hline & 2.50 & 96 & 2.4 & 98 & 3.2 \\
\hline \multirow[t]{2}{*}{ Sunflower-2 } & 0.25 & 78 & 3.8 & 93 & 4.2 \\
\hline & 2.50 & 98 & 2.7 & 100 & 2.2 \\
\hline \multirow[t]{2}{*}{ Sunflower-3 } & 0.25 & 90 & 4.3 & 87 & 4.6 \\
\hline & 2.50 & 99 & 4.0 & 106 & 5.2 \\
\hline \multirow[t]{2}{*}{ Corn } & 0.25 & 86 & 5.4 & 79 & 5.5 \\
\hline & 2.50 & 90 & 2.5 & 87 & 2.0 \\
\hline \multirow[t]{2}{*}{ Hazelnut } & 0.25 & 92 & 3.2 & 86 & 4.7 \\
\hline & 2.50 & 104 & 3.4 & 98 & 4.4 \\
\hline
\end{tabular}

RR: Relative recovery

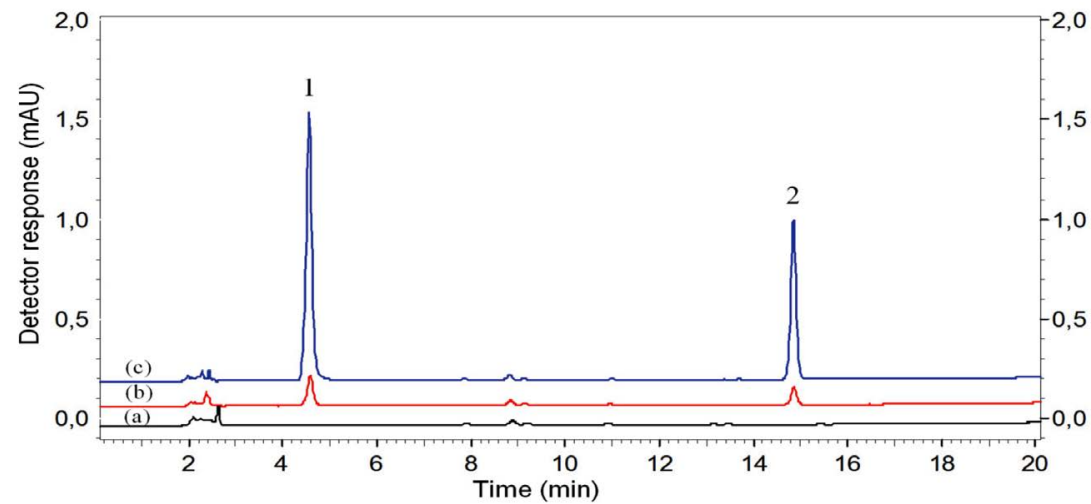

Figure 7. HPLC-UV chromatograms, corresponding to (a) sunflower oil sample, and the same sample after spiking of the alkyl gallates at the (b) $0.25 \mu \mathrm{g} \mathrm{g}^{-1}$ and (c) $2.5 \mu \mathrm{g} \mathrm{g}^{-1}$ levels. 1: Propyl gallate, 2: Octyl gallate. 
Table 4. Comparison of the proposed method with other methods used in determination of alkyl gallates in vegetable oil samples.

\begin{tabular}{|c|c|c|c|c|c|c|c|c|c|}
\hline Method & Analytes & $\begin{array}{c}\text { Sample } \\
\text { amount (g) }\end{array}$ & $\begin{array}{c}\text { Extraction } \\
\text { solvent }\end{array}$ & $\begin{array}{c}\text { Solvent } \\
\text { volume }(\mathrm{mL})\end{array}$ & $\begin{array}{l}\text { Extraction } \\
\text { time (min) }\end{array}$ & $\begin{array}{c}\text { RSD } \\
(\%)\end{array}$ & LOD & $\begin{array}{c}\text { Recovery } \\
(\%)\end{array}$ & Reference \\
\hline $\begin{array}{l}\text { CPE-HPLC- } \\
\text { DAD }\end{array}$ & $\begin{array}{l}\text { Propyl } \\
\text { gallate }\end{array}$ & 2 & Triton X-114 & 5 & 30 & $<2.2$ & $1.9 \mu \mathrm{g} \mathrm{L}^{-1}$ & $86-88$ & 10 \\
\hline $\begin{array}{l}\text { UAE-HPLC- } \\
\text { UV }\end{array}$ & $\begin{array}{l}\text { Propyl } \\
\text { gallate }\end{array}$ & 10 & $\begin{array}{l}\text { Methanol + } \\
\text { acetonitrile }\end{array}$ & 45 & 15 & $<4.0$ & $300 \mu \mathrm{g} \mathrm{L}^{-1}$ & $103-108$ & 11 \\
\hline $\begin{array}{l}\text { LLE-LC- } \\
\text { TOF-MS }\end{array}$ & $\begin{array}{c}\text { Propyl } \\
\text { gallate } \\
\text { Octyl gallate }\end{array}$ & 0.25 & $\begin{array}{l}\text { Acetonitrile + } \\
\text { hexane }\end{array}$ & 3 & 5 & $<6.3$ & $\begin{array}{l}20 \mu \mathrm{g} \mathrm{kg}^{-1} \\
20 \mu \mathrm{g} \mathrm{kg}^{-1}\end{array}$ & $82-96$ & 12 \\
\hline $\begin{array}{l}\text { DLLME- } \\
\text { HPLC- } \\
\text { DAD }\end{array}$ & $\begin{array}{c}\text { Propyl } \\
\text { gallate } \\
\text { Octyl gallate }\end{array}$ & 0.025 & $\begin{array}{c}\text { Hexane + } \\
\text { acetonitrile }\end{array}$ & 1 & 2 & $<2.7$ & $\begin{array}{l}10 \mu \mathrm{g} \mathrm{L}^{-1} \\
15 \mu \mathrm{g} \mathrm{L}^{-1}\end{array}$ & $94-105$ & 5 \\
\hline $\begin{array}{l}\text { DLLME- } \\
\text { MSPE- } \\
\text { HPLC-UV }\end{array}$ & Propyl gallate & 2 & Heptanol & 0.16 & $\sim 3$ & $<6.7$ & $1.2 \mu \mathrm{g} \mathrm{L}^{-1}$ & $90-92$ & 20 \\
\hline $\begin{array}{l}\text { VA-DES- } \\
\text { LLME- } \\
\text { HPLC-UV }\end{array}$ & $\begin{array}{c}\text { Propyl } \\
\text { gallate } \\
\text { Octyl gallate }\end{array}$ & 1 & $\begin{array}{l}\text { ChCl:ethylene } \\
\text { glycol DES }\end{array}$ & 0.12 & 5 & $<7.5$ & $\begin{array}{l}2.1 \mu \mathrm{g} \mathrm{kg}^{-1} \\
4.6 \mu \mathrm{g} \mathrm{kg}^{-1}\end{array}$ & $78-106$ & $\begin{array}{l}\text { This } \\
\text { study }\end{array}$ \\
\hline
\end{tabular}

DAD: diode array detection; MSPE: magnetic solid-phase extraction; TOF-MS: time-of-flight-mass spectrometry; UAE: ultrasonic-assisted extraction

fore and after spiking. No interfering peaks from the sample matrix or DES solvent were observed at the retention times of compounds of interest, which demonstrated the good applicability of the proposed method.

Extraction and determination of alkyl gallates in vegetable oils by the proposed method was compared with those of other methods considering the performance parameters such as sample amount, type and volume of extraction solvent, extraction time, RSD, LOD, and relative recovery. The details of the comparison are summarized in Table 4. As shown, the proposed method offers lower consumption of sample amount and solvent volume, faster analyses, and lower detection limits than most of the existing methods while being comparable with respect to the precision and accuracy. More importantly, by using DES instead of conventional solvents, the main merits of the proposed method such as simplicity, low cost, and environmental benignity were enhanced.

\section{Conclusions}

A green and efficient analytical methodology (VADES-LLME-HPLC-UV) was developed for the extraction and analysis of alkyl gallates (propyl gallate and octyl gallate) in vegetable oil samples. The ChCl:ethylene glycol DES proved to be an excellent solvent for alkyl gallates of low and medium polarity thanks to the hydrogen bonding interaction between the phenyl hydroxyl groups and anion of choline salt. Vortex stirring was employed to promote the dispersion of the DES solvent into the oil sample, which resulted in high extraction efficiency with the obtained extraction recoveries ranging from 73 to $93 \%$. The optimized procedure displayed a good precision with RSDs $<7.5 \%$ and reliable analytical results with spiked recoveries (accuracies) in the range of 78-106\%. LODs were in the range of 2.1-4.6 $\mathrm{g} \mathrm{kg} \mathrm{k}^{-1}$, which is better than or comparable with other reported approaches applied to the determination of alkyl gallates in vegetable oils.

\section{Acknowledgements}

The authors would like to thank to Zonguldak Bülent Ecevit University for the opportunity and financial support.

\section{References}

1. D. W. Sin, Y. C. Wong, C. Y. Mak, S. T. Sze, W. Y. Yao, J. Food Compos. Anal. 2006, 19, 784-791.

DOI:10.1016/j.jfca.2005.12.005

2. F. Shahidi, P. Ambigaipalan, J. Funct. Foods 2015, 18, 820-897. DOI:10.1016/j.jff.2015.06.018

3. Y. Hou, Z. Xie, H. Cui, Y. Lu, T.Zheng, S. Sang, L. Lv, Food Chem. 2018, 269, 396-403. DOI:10.1016/j.foodchem.2018.07.030

4. I. C. Silva, C. R. Polaquini, L. O. Regasini, H. Ferreira, F. R. Pavan, Food Chem. Toxicol. 2017, 105, 300-307.

DOI:10.1016/j.fct.2017.04.033 
5. S. Xu, L. Liu, Y. Wang, D. Zhou, M. Kuang, D. Fang, W. Yang, S. Wei, A. Xiao, L. Ma, J. Sep. Sci. 2016, 39, 3205-3211. DOI: 1 https://doi.org/10.1002/jssc.201600434

6. U. Sivasankaran, A. E. Vikraman, D. Thomas, K. G. Kumar, Food Anal. Methods 2016, 9, 2115-2123. DOI:10.1007/s12161-015-0356-7

7. M. Cui, J. Huang, Y. Wang, Y. Wu, X. Luo, Biosens. Bioelectron. 2015, 68, 563-569. DOI:10.1016/j.bios.2015.01.029

8. G. Xu, Y. Chi, L. Li, S. Liu, X. Kan, Food Chem. 2015, 177, 37-42. DOI:10.1016/j.foodchem.2014.12.097

9. J.-M. Kim, S.-H. Choi, G.-H. Shin, J.-H. Lee, S.-R. Kang, K.-Y. Lee, H.-S. Lim, T. S. Kang, O.-H. Lee, Food Chem. 2016, 213, 19-25. DOI:10.1016/j.foodchem.2016.06.053

10. M. Chen, Q. Xia, M. Liu, Y. Yang, J. Food Sci. 2011, 76, C98C103. DOI:10.1111/j.1750-3841.2010.01914.x

11. B. Saad, Y. Y. Sing, M. A. Nawi, N. Hashim, A. S. M. Ali, M. I. Saleh, S. F. Sulaiman, K. M. Talib, K. Ahmad, Food Chem. 2007, 105, 389-394.

DOI: https://doi.org/10.1016/j.foodchem.2006.12.025

12. L. Xiu-Qin, J. Chao, S. Yan-Yan, Y. Min-Li, C. Xiao-Gang, Food Chem. 2009, 113, 692-700.

DOI:10.1016/j.foodchem.2008.07.072

13. Y. Guan, Q. Chu, L. Fu, T. Wu, J. Ye, Food Chem. 2006, 94, 157-162. DOI:10.1016/j.foodchem.2005.01.015

14. M. M. Delgado-Zamarreno, A. Sanchez-Perez, I. G. Maza, J. Hernandez-Mendez, J. Chromatogr. A 2000, 871, 403-414. DOI:10.1016/S0021-9673(99)01020-1

15. Q. Xiang, Y. Gao, Y. Xu, E. Wang, Anal. Sci. 2007, 23, 713717. DOI:10.2116/analsci.23.713

16. H.-Y. Huang, Y.-J. Cheng, C.-L. Lin, Talanta 2010, 82, 14261433. DOI:10.1016/j.talanta.2010.07.014

17. G. K. Ziyatdinova, A. A. Saveliev, G. A. Evtugyn, H. C. Budnikov, Electrochim. Acta 2014, 137, 114-120.

DOI:10.1016/j.electacta.2014.06.009

18. J.-Y. Wang, H.-L. Wu, Y.-M. Sun, H.-W. Gu, Z. Liu, Y.-J. Liu, R.-Q. Yu, J. Chromatogr. B 2014, 947, 32-40.

DOI:10.1016/j.jchromb.2013.12.009

19. J.-Y. Wang, H.-L. Wu, Y. Chen, Y.-M. Sun, Y.-J. Yu, X.-H. Zhang, R.-Q. Yu, J. Chromatogr. A 2012, 1264, 63-71.

DOI:10.1016/j.chroma.2012.09.070

20. X. Li, D. Meng, L. Zhang, J. Zhao, Y. Yang, Sep. Sci. Technol. 2018, 53, 2224-2231. DOI:10.1080/01496395.2018.1446983

21. Z.-L. Huang, B.-P. Wu, Q. Wen, T.-X. Yang, Z. Yang, J. Chem. Technol. Biotechnol. 2014, 89, 1975-1981. DOI: $10.1002 /$ jctb. 4285

22. T. Khezeli, A. Daneshfar, R. Sahraei, Talanta 2016, 150, 577585. DOI:10.1016/j.talanta.2015.12.077

23. M. Ruesgas-Ramón, M. C. Figueroa-Espinoza, E. Durand, J. Agric. Food Chem. 2017, 65, 3591-3601.

DOI:10.1021/acs.jafc.7b01054

24. H. Wang, L. Hu, X. Liu, S. Yin, R. Lu, S. Zhang, W. Zhou, H.
Gao, J. Chromatogr. A 2017, 1516, 1-8. DOI:10.1016/j.chroma.2017.07.073

25. A. García, E. Rodríguez-Juan, G. Rodríguez-Gutiérrez, J. J. Rios, J. Fernández-Bolaños, Food Chem. 2016, 197, 554-561. DOI:10.1016/j.foodchem.2015.10.131

26. M. C. Bubalo, N. Ćurko, M. Tomašević, K. K. Ganić, I. R. Redovniković, Food Chem. 2016, 200, 159-166.

DOI:10.1016/j.foodchem.2016.01.040

27. W. Bi, M. Tian, K. H. Row, J. Chromatogr. A 2013, 1285, 2230. DOI:10.1016/j.chroma.2013.02.041

28. Q. Cui, J.-Z. Liu, L.-T. Wang, Y.-F. Kang, Y. Meng, J. Jiao, Y.-J. Fu, J. Cleaner Prod. 2018, 184, 826-835. DOI:10.1016/j.jclepro.2018.02.295

29. B. Tang, W. Bi, H. Zhang, K. H. Row, Chromatographia 2014 , 77, 373-377. DOI:10.1007/s10337-013-2607-3

30. C. Florindo, L. C. Branco, I. M. Marrucho, Fluid Phase Equilib. 2017, 448, 135-142. DOI:10.1016/j.fluid.2017.04.002

31. P. Makoś, A. Przyjazny, G. Boczkaj, J. Chromatogr. A 2018, 1570, 28-37. DOI:10.1016/j.chroma.2018.07.070

32. D. Ge, Y. Zhang, Y. Dai, S. Yang, J. Sep. Sci. 2018, 41, 16351643. DOI:10.1002/jssc.201701282

33. W. Liu, K. Zhang, J. Chen, J. Yu, J. Mol. Liq. 2018, 260, 173179. DOI:10.1016/j.molliq.2018.03.092

34. W. Liu, B. Zong, J. Yu, Y. Bi, Food Anal. Methods 2018, 11, 1797-1803. DOI:10.1007/s12161-018-1174-5

35. W. Liu, K. Zhang, J. Yu, Y. Bi, Food Anal. Methods 2017, 10, 3209-3215. DOI:10.1007/s12161-017-0891-5

36. A. Makahleh, B. Saad, M. F. Bari, in: F. Shahidi (Ed.): Handbook of antioxidants for food preservation, Woodhead Publishing, Cambridge, 2015, pp. 51-78.

DOI:10.1016/B978-1-78242-089-7.00003-8

37. C. André, I. Castanheira, J. M. Cruz, P. Paseiro, A. Sanches-Silva, Trends Food Sci. Technol. 2010, 21, 229-246. DOI:10.1016/j.tifs.2009.12.003

38. Q. Zhang, K. D. O. Vigier, S. Royer, F. Jerome, Chem. Soc. Rev. 2012, 41, 7108-7146. DOI:10.1039/c2cs35178a

39. M. H. Zainal-Abidin, M. Hayyan, A. Hayyan, N. S. Jayakumar, Anal. Chim. Acta 2017, 979, 1-23.

DOI:10.1016/j.aca.2017.05.012

40. L. Vieira, R. Schennach, B. Gollas, Phys. Chem. Chem. Phys. 2015, 17, 12870-12880. DOI:10.1039/C5CP00070J

41. M. Hayyan, A. Abo-Hamad, M. A. AlSaadi, M. A. Hashim, Nanoscale Res. Lett. 2015, 10, 1-26.

DOI:10.1186/s11671-015-1004-2

42. N. Li, L. Zhang, L. Nian, B. Cao, Z. Wang, L. Lei, X. Yang, J. Sui, H. Zhang, A. Yu, J. Agric. Food Chem. 2015, 63, $2154-$ 2161. DOI:10.1021/jf505760y

43. P. Reboredo-Rodríguez, L. Rey-Salgueiro, J. Regueiro, C. González-Barreiro, B. Cancho-Grande, J. Simal-Gándara, Food Chem. 2014, 150, 128-136.

DOI:10.1016/j.foodchem.2013.10.157 


\section{Povzetek}

V tej študiji raziskujemo možnost uporabe hidrofilnih močnih evtektičnih topil (DES) kot zelenih in učinkovitih ekstraktantov za ekstrakcijo in predkoncentracijo alkil galatov iz rastlinskih olj. V tipičnem poskusu smo dodali $120 \mu \mathrm{L}$ DES-a holin klorid:etilen glikol k 1,0 g vzorca olja, ki smo ga predhodno razredčili z $1 \mathrm{~mL} n$-heksana. Ekstrakcijo smo pospešili $z$ vrtinčastim mešanjem obeh faz. $V$ tem koraku je bil verjetno glavni razlog za ekstrakcijo nastanek vodikovih vezi med fenil-hidroksilno skupino alkil galatov in kloridom iz holin klorida. Po ekstrakciji smo analite iz DES-faze ločili in določili z visokoločljivostno tekočinsko kromatografijo z ultravijolično detekcijo. Meje zaznave so bile $2,1 \mu \mathrm{g} \mathrm{kg}{ }^{-1} \mathrm{za}$ propil galat in $4,6 \mu \mathrm{g} \mathrm{kg}^{-1} \mathrm{za}$ oktil galat. Natančnost metode je bila 4,6-6,4\% (znotraj dneva) in 5,4-7,5\% (med dnevi). Izkoristki (pravilnost) za vzorce rastlinskega olja $\mathrm{z}$ dodanimi analiti so bili v območju 78-106\%. 